\title{
The Consequences of Forced Migration for Host Communities in Africa
}

\begin{abstract}
This paper reviews the evidence on the consequences of hosting forced migrants (i.e. refugees or internally displaced persons) in Africa. Overall, the presence of forced migrants is positive for local economies, but there are multiple consequences of hosting displaced populations and some could be negative (e.g. environmental damage, competition for resources, labour market displacement). The implications of hosting forced migrants are also likely to be different across sectors of the host population and several papers identify 'winners' and 'losers' among the host community members. Finally, the impacts of hosting forced migrants can have long-lasting consequences and change the hosting communities even after the forced migrants have left. The paper also identifies several key gaps in the literature. Among these gaps, the lack of research on the consequences of hosting internally displaced persons and the scarce evidence on the implications of refugee repatriation for communities of return standout as particularly important.
\end{abstract}

Keywords: refugees, displacement, Africa, labour markets

\author{
Isabel Ruiz \\ Harris Manchester College \\ University of Oxford \\ Mansfield Rd, Oxford OX1 3TD \\ United Kingdom \\ isabel.ruiz@hmc.ox.ac.uk \\ Carlos Vargas-Silva \\ Centre on Migration, Policy and Society \\ University of Oxford \\ 58 Banbury Rd, Oxford OX2 6QS \\ United Kingdom \\ carlos.vargas-silva@compas.ox.ac.uk
}




\section{Introduction}

This paper reviews the evidence on the consequences of hosting forced migrants in Africa. This topic is of primary importance for the continent as it hosts close to one third of the displaced population worldwide. In fact, the number of displaced people in Africa doubled from 10 to 20 million between 2011 and 2016 (UNHCR, 2016). There are multiple conflicts across the continent and some have lasted, in some form or another, for several decades (e.g. Burundi, DRC, Somalia). Some African countries are also among the poorest of the world and the least equipped to host large displaced populations.

While research on the economic consequences of displacement is still relatively small, Africa is the region of the world in which more research has been conducted. The existing research covers topics that range from labour market outcomes and income to health and environmental factors. Many of these papers have been presented at the annual conference of Migration and Development or have been authored by participants in the conference.

Reviewing the evidence on the consequences of displacement for Africa yields a number of insights. First, most of the evidence is about hosting international refugees and there is scarce evidence on the consequences of hosting internally displaced persons (IDPs). Second, there are some aspects of the impacts of hosting refugees in Africa that are not much different from those found in the broader literature on the impacts of immigration. Overall, the presence of refugees seems to be positive for local economies, but there are multiple consequences of hosting displaced populations and some could be negative (e.g. environmental damage, competition for resources, labour market displacement). Third, the implications of hosting forced migrants are likely to be different across sectors of the host population. Several papers identify 'winners' and 'losers' among the host community members from a refugee shock. Fourth, the impacts of hosting refugees can have long-lasting consequences and change the hosting communities even after refugees have left. Finally, there is no much evidence on the consequences of refugee repatriation for communities of return. This is an important gap in the evidence given the major 
emphasis on return policies at the moment in response to the increase in asylum applications in Europe.

The rest of the discussion in this paper is as follows. Section 2 summarises the key statistics and trends on displacement in Africa. Section 3 explores the evidence about impacts on labour markets and economic activities. Section 4 discusses the evidence about impacts on prices, income and consumption. Section 5 presents the evidence on impacts on non-economic factors. Finally, Section 6 discusses the key remaining gaps in the literature.

\section{Displacement in Africa}

There were close to 20 million displaced persons in Africa in 2016, which accounted for about one third of the displaced population worldwide. This includes 5.6 million refugees, 13.2 million IDPs, and 715,000 stateless people (UNHCR, 2016). Most of the research on displacement in Africa has been conducted in countries either in Central Africa and the Great Lakes region or in the East and Horn of Africa region. Popular countries for research include Burundi, DRC, Kenya, Rwanda, Somalia, South Sudan, Tanzania and Uganda.

The quality of the data on forced migration differs by type of displacement. Data on refugees (including those in "refugee" like situations) tend to be more precise than data on IDPs, as typically there is some form of registration process which involves international organisations. Therefore, we start the discussion looking at data and population dynamics related to refugees. To illustrate a common dynamic of refugee populations in Africa, we focus on two key displaced groups, Somalis in Kenya and Burundians in Tanzania.

First, note from Figure 1 that there have been sudden movements in both refugee populations over time. For instance, the number of Burundians in Tanzania increased from close to 150,000 to close to 445,000 in one year (1992 to 1993). Likewise, the number of Somalians in Kenya tripled from 1991 to 1992 . This is one key characteristic of refugee movements within Africa (and in many other regions). The changes in the flow of refugees are often sudden, which means that host communities are unlikely to be prepared to receive large numbers of refugees. In 
contrast, in the "economic migration" context there tends to be a more gradual increase in the population. The sudden nature of refugee movements also has implications for other factors associated with large migration movements, such as remittances. Even if the displaced would like to start sending or receiving remittances soon after migration, remittances businesses can take a while to start operating (Vargas-Silva, 2017). Also, limited options for receiving/sending remittances in this initial stage and lack of competition among providers can result in higher fees for these services.

[Figure 1]

Second, in both situations, as it is often the case in Africa, most refugees had to travel on foot to the neighbouring country (Fransen et al., 2017; Ruiz and Vargas-Silva, 2015, 2016). This suggests that the trajectory and final location of refugees is largely determined by distance and other geographical factors (e.g. forests, mountains). Moreover, neighbouring host countries typically keep refugee camps as close to the border as possible (Jaspers, 1994; Whitaker, 1999). This facilitates repatriation later and it is cost effective given the expenses associated with transporting refugees to other regions (Maystadt and Verwimp, 2014). As seen in Figure 2, this is the case in Kenya and Tanzania. The Dadaab camp complex in Kenya is close to the border with Somalia, and the same goes for the current camps in Tanzania (i.e. close to the border with Burundi). Kenya also has a second large refugee complex in the Turkana region (Kakuma) that was established following the arrival of refugees from Sudan and it is also close to the border with South Sudan.

[Figure 2]

The implication of the two factors discussed above related to the timing of displacement and location of refugees, explains why many academic papers have taken refugee movements in Africa as quasi-experimental situations. This approach addresses many of the potential concerns about endogeneity in the traditional economics of immigration literature (Ruiz and Vargas-Silva, 2013). Therefore, refugee flows in Africa are interesting, not only for their magnitude and the 
nature of the countries involved, but also from a methodological standpoint as it is possible to explore the consequences of an 'exogenous' increase in the immigrant population.

The story is somewhat different for IDPs. In most cases, these are much more difficult to identify as most of the time there is no formal registration process. Also, while factors such as distance still play a role in the ultimate location of the internally displaced, the location of IDP settlements is much more spontaneous and less restricted that in the case of refugees. Many of those internally displaced just move to other communities on their own or join family members in other parts of the country. They also move from rural settings into urban peripheries of large African cities (Alix-Garcia et al., 2013) or become refugees in urban settings possibly speeding up the urbanization process. This is one reason for which there is less empirical evidence on the consequences of hosting IDPs. This is a major limitation. As shown by Figure 3, many countries in Africa have had an estimate of over 500,000 IDPs at some point during the last three decades. Also, as mentioned above, the overall number of IDPs in Africa is estimated to be much larger than the number of refugees.

[Figure 3]

Figure 4 presents the number of refugees which return to African countries each year. In some of the years (particularly during the 1990s) the number was substantially above the 500,000 mark. The number of refugees returning home decreased substantially during the 2000s. This was the result of an increase in the number of "protracted emergencies", which has led to a historically high number of refugees worldwide (Crisp and Long, 2016).

[Figure 4]

\section{Labour markets and economic activities}

\subsection{Conceptual background}

The impact of refugees on host labour markets will depend on the degree of substitutability between natives and refugees as well as restrictions imposed by the host country on the labour market participation and movement of refugees. 
The degree of substitutability between natives and refugees will be affected by linguistic and cultural similarities. It is common for individuals on opposite sides of an international border in Africa to speak the same language, belong to the same ethnic group and be otherwise similar. This largely reflects the arbitrary nature of borders in Africa (Michalopoulos and Papaioannou, 2016) and suggests that they could be close substitutes in the labour market (Ruiz and Vargas-Silva, 2016).

It is also common for host countries to impose restrictions on the access of refugees to the labour market (Zetter and Ruaudel, 2016) or on refugee movements around camp locations. For instance, Ongpin (2008) explains that a few years after the arrival of the refugees, Tanzania introduced restrictive legislation that prohibited refugees from possessing farms or owning land within the camps and from seeking employment outside the camps. As such, many refugees in Africa will be mainly working informally in agricultural or other casual waged work. Given their vulnerable situation they might be likely to accept a lower wage than low-skilled native workers in order to do similar work and even accept food as payment. There is substantial anecdotic evidence that this is the case. For instance, Whitaker (1999) suggest that the wages of refugees in Tanzania were 20 to $50 \%$ lower than those of native agricultural workers and that after the arrival of the refugees, the wage paid to casual workers dropped by half in many areas. There is likely to be less participation of refugees in non-agricultural work outside the household, which include things such as government employment from which refugees are mostly excluded (Ruiz and Vargas-Silva, 2015).

The evidence from displacement situations suggests that the demand for specific products and services in the affected region is also influenced by the presence of refugees and employees of non-governmental and international organizations assisting with the crisis (AlixGarcia et al., 2012). Natives have an advantage in establishing new businesses as they have more knowledge about the local customs and better access to key networks (Maystadt and Verwimp, 2014). This could lead to a reallocation across economic activities on the part of natives 
particularly to an increase in self-employment and, to some degree, into jobs at these organisations.

Previous studies have also documented an increase in demand for different types of crops after the arrival of refugees (Alix-Garcia and Saah, 2009). Therefore, it is possible for natives mainly working on agriculture to remain in the same activity but to change the types of crops that they are cultivating (Ruiz and Vargas-Silva, 2016). The increase in demand for some agricultural products could also possibly bring about changes in the intra-household allocation of activities and labour. The increased in demand for subsistence food crops and the possibility of generating cash could mean that, in those communities in which cash crops are typically male dominated while subsistence farming is left to the women, males would take over what was traditionally managed by females in the household.

\subsection{Evidence on labour markets and economic activities}

The evidence found in the empirical literature, as described above, seems to point to some sections of the local population facing stronger competition than others. For instance, Maystadt and Verwimp (2014), using 1991 and 2004 data for the Kagera region in Tanzania - which was host to a substantial number of refugees from Rwanda and Burundi -, find a positive aggregate effect of the presence of refugees on native welfare. However, the impact of hosting refugees on natives was heterogeneous. They find that agricultural workers in Kagera suffered the most due to the increased competition in labour markets (and increased prices), while self-employed farmers benefit from the presence of refugees and the additional supply of a cheap labor force.

Looking at the same region of Kagera, but focusing on the difference between 1991 and 2010, Ruiz and Vargas-Silva (2015), find that greater exposure to the refugee shock resulted in Tanzanians having a lower likelihood of working outside the household as employees. However, the native employees that were more affected by the shock, had afterwards a higher probability of being in professional occupations and being part of a pensions program. Ruiz and VargasSilva (2016), explored this result further and find that the lower likelihood of working outside the 
household was particularly strong for Tanzanians doing casual work before the shock. This coincides with the anecdotal evidence explained above of refugees concentrating in casual waged work in Tanzania and competing directly with Tanzanians for those jobs.

Ruiz and Vargas-Silva (2017) go further and explore whether the refugee shock in Tanzania altered the intra-household allocation of tasks across genders in the hosting population. They find that the refugee shock led to women being less likely to engage in employment outside the household and more likely to engage in household chores relative to men. This is probably the result of the environmental degradation that accompanied the arrival of refugees and the additional competition for natural resources such as wood and water. The authors explained that the arrival of refugees in rural areas often leads to greater demand for resources such as firewood and water, resulting in deforestation of areas close to refugee settlements (see Section 4.2 for further discussion of the environmental impact of refugees). In rural Tanzania it is common for households to collect firewood for cooking and fetch drinking water on a frequent basis—-tasks that are typically the responsibility of women, and additional time spent on these tasks can restrict their involvement in income-generating activities.

Using household data from Kenya, Alix-Garcia et al. (2018) also find a positive aggregate effect of the presence of refugees in the Kakuma camp on the host population (the Turkana region) in Kenya. When looking at the driving channels and the labour market dynamics, they find that on the aggregate, proximity to the camp is associated with additional low-skill jobs and waged labour. The increased population driven market-demand and the opportunities generated by camp activities seem to outweigh the competition in the labour markets. As was the case in Ruiz and Vargas-Silva (2017), the results of Alix-Garcia et al (2018) depend on educational level and seem to be specific to households with secondary education.

Finally, Loschmann et al. (2017) look at the case of three Congolese refugee camps in Rwanda. They analyse the impact of the refugee camps on the hosting communities and find similar results to some of those highlighted above. Individuals living closer to the camps are 
more likely to be involved in wage employment. They also find a strong gender component as women living closer to camps are more likely to be involved in self-employment in business both as primary and secondary activities. ${ }^{1}$

\section{Prices, Income, and Consumption}

\subsection{Conceptual background}

An influx of refugees represents an increase in the total population of a region and, as such, it increases the total demand for (sometimes locally produced) goods and services. Refugees and non-governmental organisations often buy goods and services from the local host population and refugees have been reported to frequently engage in trade with and work for locals (Betts et al., 2014; Enghoff et al., 2010). This represents an increase in economic activity in the host region. The derived spillovers from such increase could be translated into an increase in income and welfare of the hosts, particularly those that are able to serve the new markets and to take advantage of the new job opportunities. In some cases, it has even been documented that there is an increase in immigration from entrepreneurs from other communities nearby the hosting areas to serve the new markets and take advantage of the new job opportunities (Maystadt and Verwimp, 2014).

However, the increase in demand may imply subsequent demand driven increases in prices which may also yield negative wealth effects for those households that cannot serve the new market and compete effectively in the labour market. The increase in the population of refugees may also have an impact on prices which differs from that of an increase in the local population, as refugees may have different preferences. Also, previous studies have documented an increase in demand for the production of aid-related goods, including different types of crops, after the arrival of refugees (Alix-Garcia and Saah, 2009). For instance, there is evidence of

\footnotetext{
${ }^{1}$ There is substantial research on the impact of refugees on labour markets in other regions of the world. See Borjas and Monras (2017), Del Carpio and Wagner (2015), Tumen (2016), Calderón-Mejía and Ibáñez (2016).
} 
international agencies increasing the demand for wood and the price of tree farms (Whitaker, 1999).

The potential impact of refugees on prices is not limited to the demand side. As discussed in Section 3, refugees may affect the production process by providing a cheaper labour force. It is also possible that features which accompany the forced migration process such as foreign aid may impact the supply side. For instance, it is common for refugees to sell their food rations (Alix-Garcia and Saah, 2009). Alloush et al. (2017) even suggests that refugees typically sell food aid at prices well below market retail prices. Using data from three Congolese refugee camps in Rwanda they find that for the most commonly sold items, maize and cooking oil, the average ratio of the price at which refugees sell to the market retail price is 0.5 and 0.8 , respectively. The selling of food rations for a low price increases the local food supply, reduces prices and could adversely affect local producers.

Along the above lines, the aggregate income and welfare impact of refugees in hosting communities is an empirical question. As in the voluntary migration context, the aggregate impacts of forced migration in host communities can also mask potential dynamics in which there are winners and losers.

\subsection{Evidence on the impact on prices}

The evidence on the impact of hosting refugees on prices points to an increase in the price of certain products, mostly non-aid food products. The aid-food related products are not as affected, due to the increased supply of these products which ameliorates the upward push in prices due to increasing demand.

An example of a study showing a demand driven increase in prices is Alix-Garcia and Saah (2009). Their study explores the impact of the refugee inflows from Burundi and Rwanda in agricultural prices in western Tanzania. Their analysis suggested that the increase in the refugee population led to price increases which are stronger the closer a specific market is to a refugee camp. They also show that there are significant increases in the prices of non-aid food items and 
more modest price effects for aid-related food items. The authors suggest that food aid ameliorates (although it does not offset completely) the impact on prices of the population increase which results from the presence of refugees.

In the case of displacement in Darfur, Alix-Garcia et al. (2012) found that an increase in the number of IDPs led to increases in prices (holding constant the amount of aid available). In particular, the authors find price increases in the food and housing markets near the cities where the IDP settlements were located. Their results point to differential impacts on prices, including a 4.2 per cent increase in the price of fava beans for a 10 per cent increase in the number of displaced people and a 3 per cent increase in the price of wheat for a 1 per cent increase in the number of displaced.

Taylor et al. (2016) rely on simulations to explore the impact of Congolese refugee camps on host communities in Rwanda. They find a small positive impact of refugees on the consumer price index (i.e. one extra refugee leads to an increase in the consumer price index of close to $0.0003 \%$ ). This price effect has key implications for the multiplier effect of the presence of refugees on the host-community's economy. In fact, the authors make the point that the spillovers from the presence of refugees are smaller when aid is in the form of food instead of cash, as there is a transaction cost of converting food to cash. ${ }^{2}$ Finally, in the Kenyan context, in the hosting region of the Kakuma camp, Alix Garcia et al (2018) finds that livestock prices are positively correlated with high refugee and aid presence. ${ }^{3}$

\subsection{Evidence on the impact on income and consumption}

As mentioned above, the impact on income and the welfare implications of hosting refugees are closely linked to the impact on prices. While the above indicates an increase in prices, the aggregate impact of hosting refugees on consumption seems to be positive as there are many other potential channels that lead to positive changes in welfare (for example, a reduction in

\footnotetext{
2 The microdata used in their study comes from three camps in Rwanda. In two of the camps aid was distributed in "cash" to refugees (via mobile phones) and in the other aid was distributed "in-kind".

${ }^{3}$ For the impact of refugees on prices in other regions of the world see Balkan and Tumen (2016) and DepetrisChauvin and Santos (2016).
} 
transport and trade costs). An example is the work by Maystadt and Duranton (2018) which looks at the case of western Tanzania. The authors find that there was a long term significant impact on the welfare of the local population. There was a positive and significant increase in real consumption per adult equivalent ten years after the inflow of refugees. A large share of refugees had left after eight years and therefore the results held even after the departure of refugees. The authors explore the possible channels driving these results and find that the transmission channel was possibly due to an improvement in infrastructure brought about from the activities of international organizations. They find a lowering of trade costs following road construction to serve refugee camps.

Also, in the case of Tanzania, Alix-Garcia and Saah (2009) found positive wealth effects (in the form of higher household assets) of refugee camps for nearby rural households. The driving mechanism of this result was likely the increase in the price of agricultural products that were produced and consumed in the hosting population. The local households were argued to have been in a better position and benefited from selling agricultural products at higher prices. On the other hand, they find negative wealth effects in the case of households in urban areas. These households were likely only buyers of agricultural goods for consumption and therefore hurt by the price increases.

Kreibaum (2015) looks at the case of Congolese refugees in Uganda. He uses three waves of the Uganda National Household Survey and finds that for the host population living near refugee settlements there is a positive and significant increase in household's consumption and in the provision of certain public services (i.e. education but not health). He finds that increasing the number of refugees per one thousand inhabitants by 10 , would on average increase the consumption of locals by $3 \%$. While the channels are not explored, the author argues that possibly, the refugees bring new opportunities to trade and to create new entrepreneurial activity.

Interestingly, there are findings in the literature that indicate that the positive impacts on consumption can be directly linked to aid disbursed by international organisations. Taylor et al 
(2016) also looks at the case of Congolese refugees but in the case of those hosted in camps in Rwanda. The authors look at three camps, one in which aid was given in kind and the other two had shifted to cash-aid. The authors find that aid brings positive income spillovers to host country businesses and households. Their findings indicate that cash-aid given to refugees increases the annual inflation adjusted income of the local economy around two camps. ${ }^{4}$ However, the impacts, although positive, are lower for in-kind food aid. A great majority of the refugees sold part of their in-kind items to the host market around the camps and, due to transaction costs, the value of the items and spillovers effects were reduced.

In the Kenyan context, Alix Garcia et al. (2018) find a positive aggregate effect of refugees on the local economy. They find that the presence of the Kakuma camp incentivises agricultural production as agricultural activity in the Turkana region occurs almost exclusively near the camp and a general increase in labour market opportunities (as discussed above) and consumption. In general, they argue that these positive impacts are partly explained by, not only more job opportunities, but also price changes that encourage new production in the agricultural and livestock markets. They also suggest that a $10 \%$ increase in the refugee population is associated with $5.5 \%$ increase in consumption.

\section{Non-economic factors}

There are many important non-economic factors brought about by the hosting of refugees that are of importance and that have economic repercussions in the short and long term. Among those, we analyse the impacts on health, wellbeing, public service delivery, conflict and changes in the environment.

\subsection{Health, subjective well-being and public service delivery}

\footnotetext{
${ }^{4}$ The authors use survey data gathered inside and outside the camps to construct general equilibrium (GE) models of the economies inside and outside the camps (10 kms radius). The GE models simulate the economy-wide impacts of refugees at two camps in which refugees were given cash aid via cell phone accounts and one in which aid was given in kind.
} 
An under-researched area on the consequences of hosting refugees is the impacts on health outcomes (including wellbeing) and public service delivery. Most of the current literature is qualitative and there are just a few studies showing aggregate quantitative impacts. As mentioned before, the scarcity of data is a main problem. In addition, theorizing about the potential effects is also relatively difficult. ${ }^{5}$ On one hand, the sudden influx of large populations can increase the risks of disease outbreaks (e.g. propagation of malaria or HIV) and competition for resources including potable water, schools and health care facilities. On the other hand, the inflow of aid and resources of international organizations may alleviate the potential overburdening of health care and educational facilities and locals may resort to sending their kids to schools in and near the camps if the service provided is of better quality.

In one of the first papers to show evidence of the health impacts of hosting refugees, Montalvo and Reynal-Querol (2007) show that the arrival of refugees is strongly associated with negative impacts on the health of the hosting population. They show, at the macro level, that the hosting of refugees (coming from high incidence malaria countries) increases significantly the rate of malaria in the hosting region. The results are drawn from a panel of countries and for the 1962-1997 period and indicate that each 1,000 additional refugees lead to between 2,000 and 2,700 new cases of malaria in host countries. The magnitude of refugee related malaria disease during that period is estimated to be around 13\% of the malaria cases reported by the World Health Organization (WHO).

A main problem with the above study, however, is that it is difficult to establish whether the results refer to a causal impact of refugees or whether this is related to other conflict related factors. Baez (2011) overcomes these causality problems by looking at the Kagera region in Tanzania and shows that there is a substantial negative impact on health outcomes of residents living close to refugee camps. He finds that these impacts hold on the short and long run (i.e. ten

\footnotetext{
${ }^{5}$ There is a literature for other regions of the world showing that refugees have poorer health than other immigrants (Chiswick et al., 2008; Giuntella et al., 2018).
} 
years after the arrival of refugees). His study reveals a quantitatively significant deterioration of children's anthropometrics (a 0.3 standard deviation difference), an increase in the incidence of infectious diseases on the range of $15-20 \%$, and a seven percentage points increase in the mortality for children under five. These results are sustained in the long run as he finds that there is reduced height in early adulthood of approximately $1.8 \mathrm{~cm}$ for those living close to camps. Baez (2011) also finds a statistically significant reduction in schooling and literacy (0.2 years and 7 percentage points).

While the above evidence points to negative impacts on health and educational outcomes, Kreibaum (2016) finds that in Uganda, for those living near refugee settlements there is a positive and significant increase in the provision of certain public services (i.e. education but not health).

\subsection{Environment}

The arrival of forced migrants is accompanied by an increase in the demand for resources such as land for cultivation, firewood and water. Forced migrants often cut down trees in order to use the wood for shelter and cooking and to clear space for cultivating crops. This leads to deforestation and land degradation. The presence of refugee camps has been associated also with soil erosion and the pollution of water resources nearby refugee camps (UNEP, 2008). In fact, forced migrants have often been categorized as 'resource degraders' (Jacobsen 1997).

Berry (2008) has found this to be the case for Western Tanzania. Her findings indicated that the rate of deforestation in this area was higher than the national average. In fact, she reported that, due to the competition for resources, the distances travelled in order to collect firewood and wood were much higher than ten years prior the arrival of refugees. This subsequently led to the unlawful cutting of trees nearby and further deforestation (Berry, 2008).

In a related literature, Alix-Garcia et al. (2013) links internal displacement to degradation in South Sudan. The authors use satellite data, statistics on IDPs, violent events and, food aid delivery, for the 2000-2007 period and they analyse how conflict leads to agricultural production 
and changes in the patters of land use. They find that the presence of IDPs in the periphery of cities led to a decrease in vegetation due to more intense land use.

\section{Summary and remaining gaps}

With over 20 million displaced persons in Africa, understanding the impacts of refugees on the hosting economy is of high policy relevance. The current economic literature shows that the consequences of hosting refugees are not unidirectional but, instead, there are both positive and negative impacts on the economy and not all the individuals are affected equally. Having a deeper understanding of the channels by which refugees affect local communities remains a challenge and an objective of this line of inquiry.

Overall, there are also many other factors related to the impact of forced displacement on host communities in Africa for which there is insufficient evidence and remain as a gap in the literature. We consider the following five areas to be particularly important areas for future research:

- Mobility and out-migration: Communities in Africa could adapt to the presence of refugees in various ways, including out-migration. For instance, there is substantial evidence of out-migration movements from communities or cities in response to immigration flows for high-income countries (e.g. Borjas, 2006). This out-migration has been highlighted as one of the factors attenuating the empirical estimates of the negative labour market impacts of immigration on previous residents. A similar dynamic could occur in the case of low-income countries, in which communities with higher levels of return migration may experience higher levels of out-migration as a result of greater demographic pressure on limited resources like land and food. However, there is scarce research on this type of adjustment in the context of a low-income country and it is essential to have further evidence in order to truly understand the consequences of hosting refugees. 
- Fiscal impacts: there is no evidence on the consequences of hosting refugees for public finances in African countries. This is in opposition to the case of high income countries where there are numerous analyses of the fiscal impact of immigration (Vargas-Silva, 2015). This gap is very important as many African countries face serious financial challenges and the financial benefit or burden of refugees can play a big role.

- Public opinion and voting: there is growing concern that hosting refugees may have implications for public opinion and support for different political parties (Dustmann, 2016; Steinmayr, 2016). However, we know very little about the implications of refugee flows in the African context.

- Impacts on communities of return: In the absence of resources and favourable conditions in areas of high return, a rapid population increase resulting from refugees returning home may lead to increased competition over valuable resources such as agricultural land and worse living conditions for all households. Existing research on return migration in a conflict context has mostly focused on the socio-economic conditions of returnees themselves (Fransen et al., 2017; Christensen et al., 2015; O’Reilly, 2015; Ruiz et al., 2015; Verwimp and Muñoz-Mora, 2017). These studies have shown that return populations are generally worse off relative to those who did not move during conflict. However, the effects of large-scale refugee repatriation on those who did not move are generally not addressed. This is an important omission as repatriation can have implications not just for returnees themselves but for other populations in areas of return as well. 


\section{References}

Alix-Garcia, J. and D. Saah (2009) “The Effects of Refugee Inflows in Host Communities: Evidence from Tanzania." World Bank Economic Review, 24(1): 148-170

Alix-Garcia, J., Bartlett, A. and D. Saah (2012) "Displaced Populations, Humanitarian Assistance and Hosts: A Framework for Analyzing Impacts on Semi-urban Households." World Development, 40: 373-386.

Alix-Garcia, J., A. Bartlett, and D. Saah (2013) “The Landscape of Conflict: IDPs, Aid and Landuse Change in Darfur." Journal of Economic Geography, 13: 589-617.

Alix-Garcia, J., Walker, S., Bartlett, A., Onder, H. and Sanghi, A. (2018) "Do Refugee Camps Help or Hurt Hosts? The Case of Kakuma, Kenya." Journal of Development Economics, 130: 6683.

Alloush, M., Talylor, J.E., Gupta, A., Rojas Valdes, R.I. and E. Gonzalez-Estrada (2017) “Economic Life in Refugee Camps.” World Development, 95: 334-347.

Baez, J. (2011) "Civil Wars beyond Their Borders: The Human Capital and Health Consequences of Hosting Refugees." Journal of Development Economics, 96: 391-408.

Balkan, B. and S. Tumen (2016) "Immigration and Prices: Quasi-experimental Evidence from Syrian Refugees in Turkey." Journal of Population Economics, 29(3): 657-686.

Berry, L. (2008) “The Impact of Environmental Degradation on Refugee-Host Relations: A Case Study from Tanzania.” New Issues in Refugee Research, Research Paper 151.

Betts, A. et al. (2014) "Refugee Economies: Rethinking Popular Assumptions." University of Oxford: Refugee Studies Centre, Humanitarian Innovation Project, www.rsc.ox.ac.uk/files/publications/other/ refugee-economies-2014.pdf

Borjas, G. (2006) "Native Internal Migration and the Labor Market Impact of Immigration." Journal of Human Resources, 41(2): 221-258.

Borjas, G and J. Monras (2017) "The Labour Market Consequences of Refugee Supply Shocks." Economic Policy, 32(91): 361-413.

Calderon-Mejia, V. and A. Ibanez (2016) "Labour Market Effects of Migration-related Supply Shocks: Evidence from Internal Refugees in Colombia." Journal of Economic Geography, 16(3): 695-713. 
Chiswick, B.R., Lee, Y.L., and P.W. Miller (2008) "Immigrant Selection Systems and Immigrant Health." Contemporary Economic Policy, 26: 555-578.

Christensen, A., Harild, N., and R. W. Zetter (2015) 'Sustainable Refugee Return: Triggers, Constraints, and Lessons on Addressing the Development Challenges of Forced Displacement." World Bank Global Program on Forced Displacement, Washington DC: World Bank Group, Available at: http://documents.worldbank.org/curated/en/542611468188337350/pdf/99618-WPPUBLIC-Box393206B-Sustainable-Refugee-Return-15Sept-WEB-PUBLIC.pdf

Crisp, J. and K. Long (2016) "Safe and Voluntary Refugee Repatriation: From Principle to Practice." Journal of Migration and Human Security, 4 (4): 141-147.

Depetris-Chauvin, E. and R. Santos (2016) "Unexpected Guests: The Impact of Internal Displacement Inflows on Rental Prices in Colombian Host Communities.” Working Paper, Available at: https://lacer.lacea.org/bitstream/handle/123456789/64561/lacea2017_impact_internal_dis placement_inflows.pdf?sequence $=1$

Del Carpio, X. and M. C. Wagner (2015) "The Impact of Syrian Refugees on the Turkish Labor Market.” Policy Research Working Paper Series 7402, The World Bank.

Dustmann, C., Vasiljeva, K. and A. Damm (2016) "Refugee Migration and Electoral Outcomes." The Rockwool Foundation Research Unit, Study Paper No. 111.

Enghoff, M., Hansen, B., Umar, A., Gildestad, B., Owen, M., and Obara, A. (2010) "In Search Of Protection and Livelihoods: Socio-economic and Environmental Impacts of Dadaab Refugee Camps on Host Communities." Report from Government of Denmark, Government of Kenya, and Government of Norway.

Fransen, S., I. Ruiz, and C. Vargas-Silva (2017). "Return Migration and Economic Outcomes in the Conflict Context." World Development, 95: 196-210.

Giuntella, O., Kone, Z.L.. Ruiz, I. and C. Vargas-Silva (2018) "Reason for Immigration and Immigrants’ Health.” Public Health, 158: 102-109.

Jacobsen, K. (1997) “Refugees' Environmental Impact: The Effect of Patterns of Settlement." Journal of Refugee Studies, 10(1): 19-36. 
Jaspers, S. (1994) “The Rwandan Refugee Crisis in Tanzania: Initial Successes and Failures in Food Assistance." Relief and Rehabilitation Network Paper 6. Overseas Development Institute, London.

Kreibaum, M. (2015) “Their Suffering, Our Burden? How Congolese Refugees Affect the Ugandan Population.” World Development, 78: 262-287.

Loschmann, C., M. Siegel and O. Bilgili, (2017) 'Considering the Benefits of Hosting Refugees: Evidence of Refugee Camps Influencing Local Labour Market Activity and Economic Welfare'. UNU-WIDER Working Paper, Maastricht University.

Maystadt, J., and G. Duranton (2018) “The Development Push of Refugees: Evidence from Tanzania." Journal of Economic Geography, forthcoming.

Maystadt, J., and P. Verwimp (2014) "Winners and Losers among a Refugee-hosting Population." Economic Development and Cultural Change, 62: 769-809.

Michalopoulos, S. and E. Papaioannou. (2016) “The Long-Run Effects of the Scramble for Africa." American Economic Review, 106(7): 1802-48.

Montalvo, J., and M. Reynal-Querol (2007) "Fighting against Malaria: Prevent Wars while Waiting for the 'Miraculous' Vaccine.” The Review of Economics and Statistics 89 (1): 165-177.

Ongpin, P. (2008). "Refugees in Tanzania, Asset or Burden?" Journal of Development and Social Transformation, 5: 13-23.

O’Reilly, C. (2015) "Household Recovery from Internal Displacement in Northern Uganda." World Development, 76: 203-215.

Ruiz, I., and C. Vargas-Silva (2013) “The Economics of Forced Migration.” Journal of Development Studies, 49(6): 772-783.

Ruiz, I., Siegel, M. and C. Vargas-Silva (2015). "Forced Up or Down? The Impact of Forced Migration on Social Status.” Journal of Refugee Studies, 8(2): 183-201.

Ruiz, I., and C. Vargas-Silva (2015) “The Labor Market Impacts of Forced Migration.” American Economic Review, 105(5): 581-86.

Ruiz, I., and C. Vargas-Silva (2016). “The Labor Market Consequences of Hosting Refugees.” Journal of Economic Geography, 16(3): 667-94. 
Ruiz, I., and C. Vargas-Silva (2017) "The Impact of Hosting Refugees on the Intra-household Allocation of Tasks: A Gender Perspective." Review of Development Economics, forthcoming.

Steinmayr, A. (2016) "Exposure to Refugees and Voting for the Far-Right: (Unexpected) Results from Austria.” IZA discussion Paper No. 9790.

Taylor, J.E., Filipski, M. Alloush, M., Gupta, A., Rojas, I. and E. Gonzalez (2016) "Economic Impact of Refugees." Proceedings of the National Academy of Sciences, 113(27): 7449-7453.

Tumen, S. (2016) “The Economic Impact of Syrian Refugees on Host Countries: QuasiExperimental Evidence from Turkey." American Economic Review, 106(5): 456-460

UNEP. (2008) Sudan: Post Conflict environmental assessment. United Nations Environment programme.

UNHCR (2016) UNHCR Global Report, African Region Summary. Retrieved from: http://www.unhcr.org/uk/publications/fundraising/593e4bf27/unhcr-global-report-2016africa-regional-summary.html

Vargas-Silva, C. (2015) “The Fiscal Impact of Immigration: Taxes and Benefits.” in Handbook on the Economics of International Migration, Eds. B.R. Chiswick and P.W. Miller. Elsevier.

Vargas-Silva, C. (2017). "Remittances Sent To and From the Forcibly Displaced." The Journal of Development Studies, 53: 1835-1848.

Verwimp, P., and J.C. Muñoz-Mora (2017) "Returning Home after Civil War: Food Security and Nutrition among Burundian Households." The Journal of Development Studies, 54(6): 10191040.

Whitaker, B. E. (1999) "Changing opportunities: Refugees and Host Communities in Western Tanzania." In New Issues in Refugee Research, Working Paper, No. 11, United Nations High Commission for Refugees.

Zetter, R. and Ruaudel, H. (2016) 'Refugees' Right to Work and Access to Labor Markets - An Assessment.” KNOMAD Working paper. World Bank: Washington, DC. 
Figure 1 - Stock of Somalian refugees in Kenya and Burundian refugees in Tanzania.

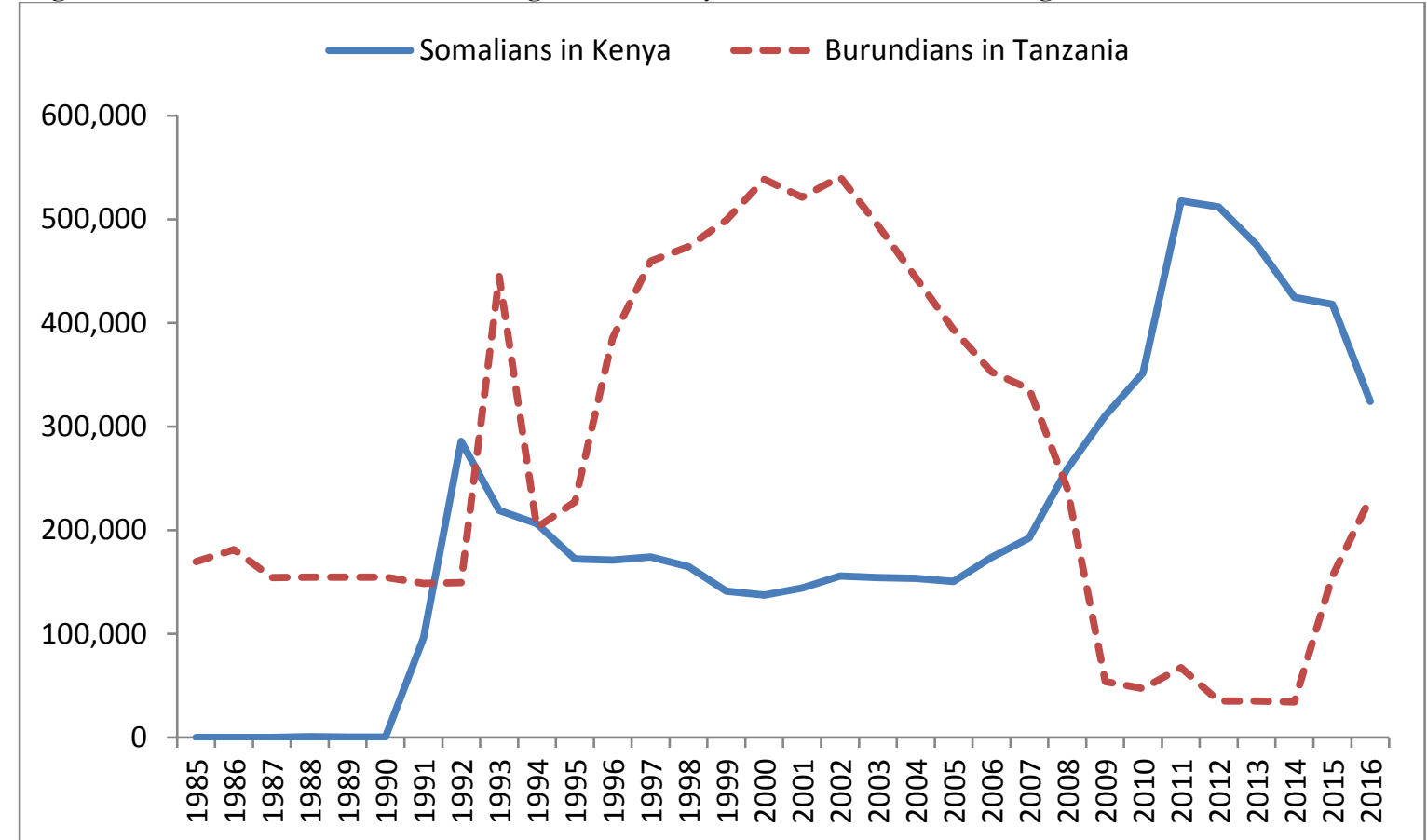

Note: Includes refugees and those in refugee-like situations.

Data source: UNHCR (2017). 
Figure 2 - Location of refugee camps in Tanzania and Kenya in 2017.

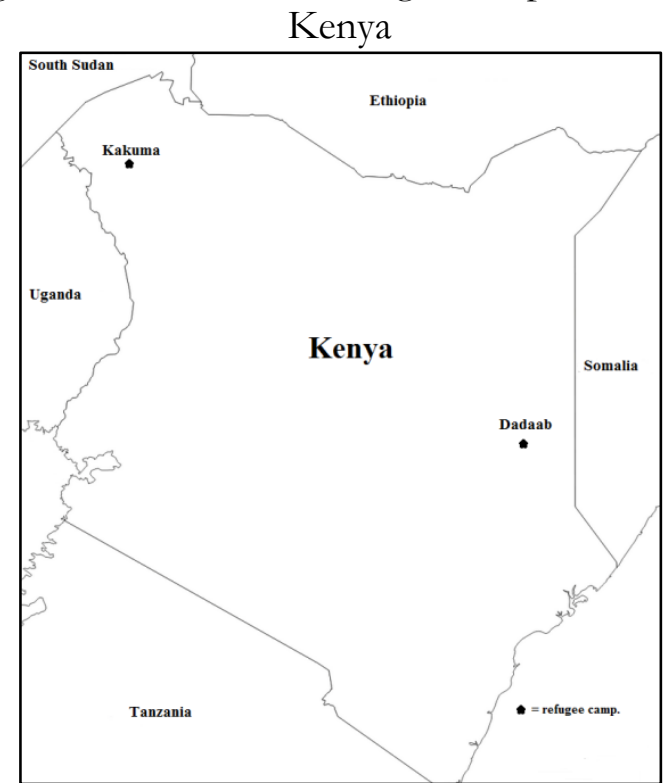

Tanzania

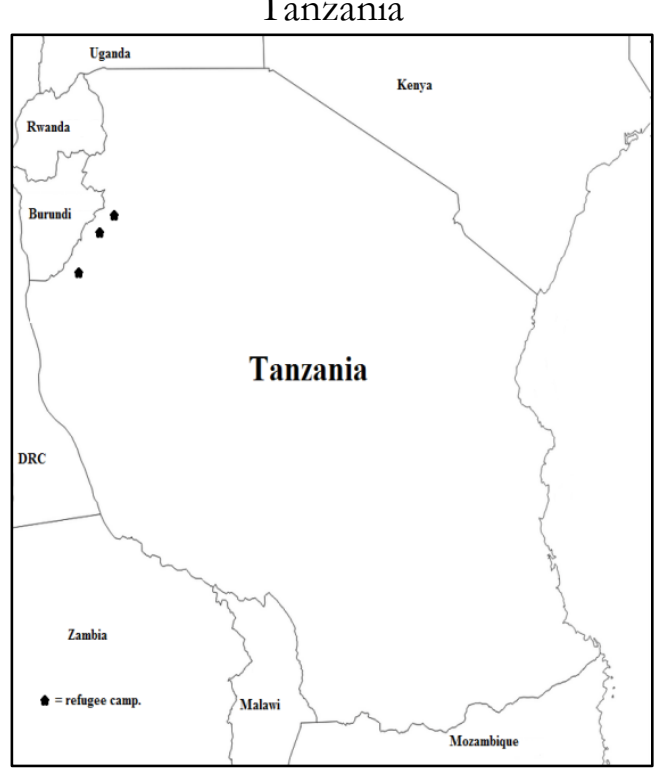

Note: In addition to these camps, these countries also host informal refugee settlements and refugees living in urban areas. Data source: UNHCR (2017). 
Figure 3 - Highest estimate of internally displaced population in several African countries and year of the estimate.

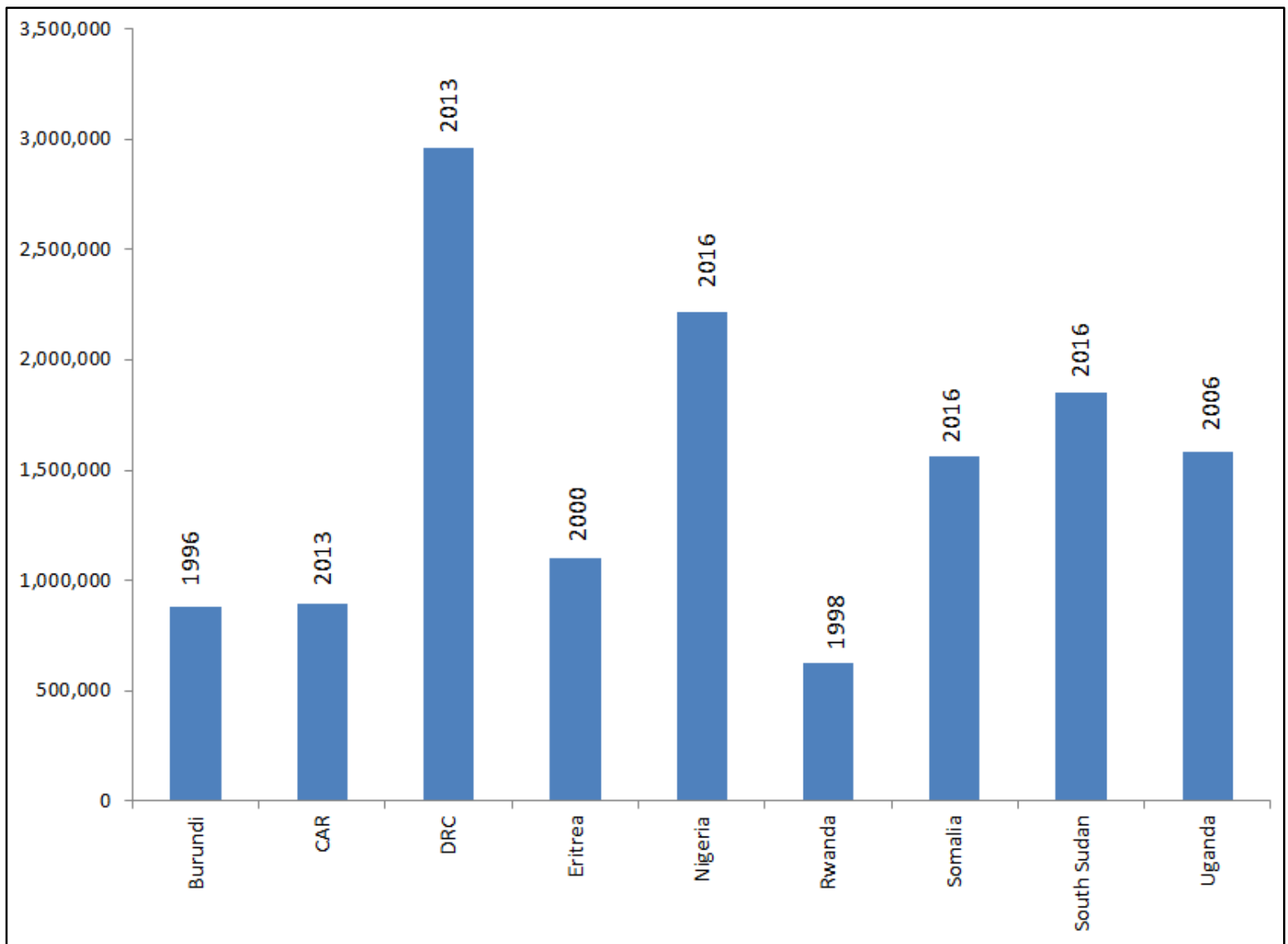

Note: The years above the columns indicate the peak years. Please note that this is not necessarily the actual peak year for actual displacement (i.e. flow), but the highest value estimated (i.e. stock). Information is missing for different years in each country.

Data source: UNHCR (2017). 
Figure 4 - Number of refugee returnees to African countries

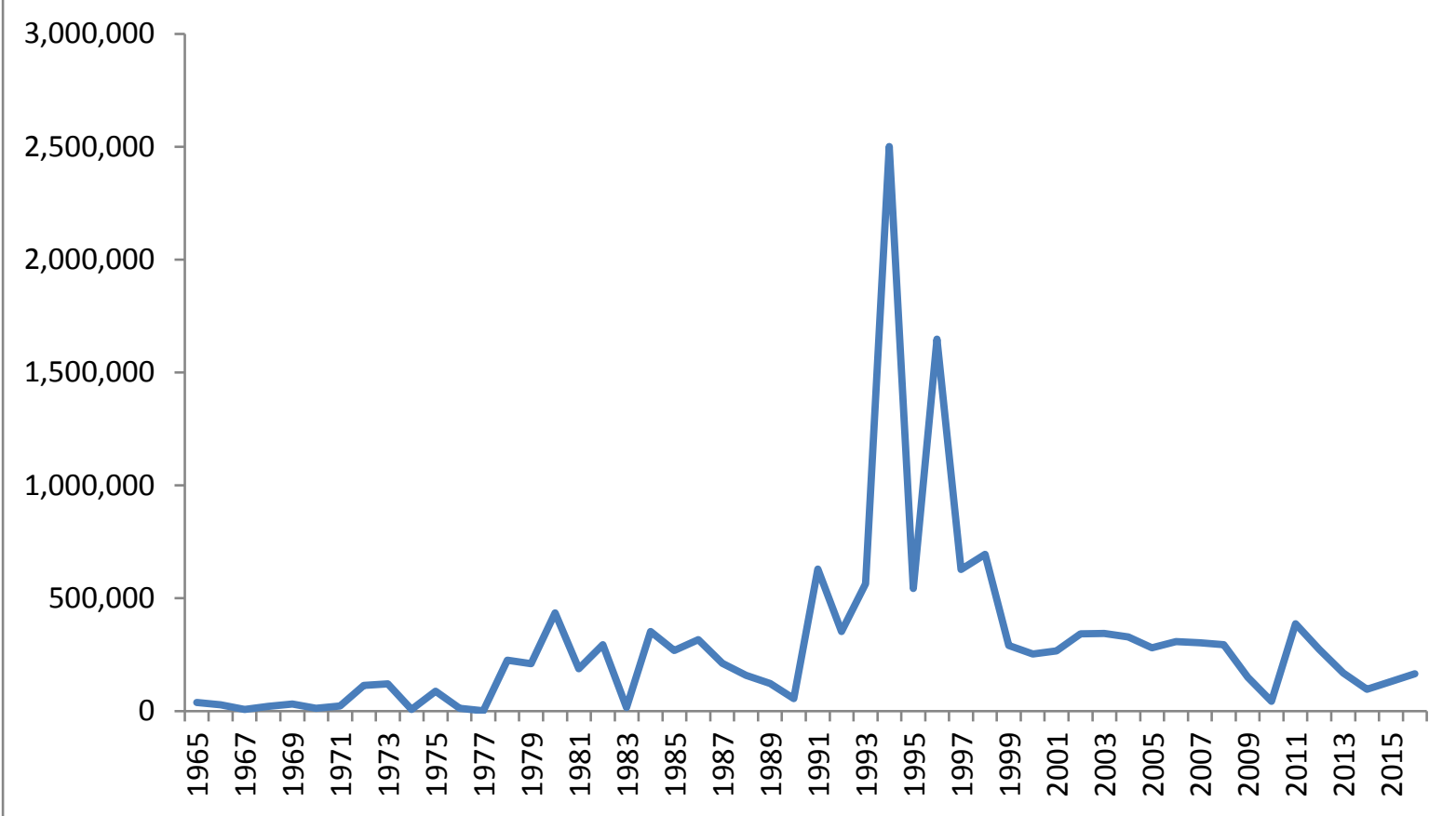

Data source: UNHCR (2017). 